\title{
Actor-partner effects associated with experiencing intimate partner violence or coercion among male couples enrolled in an HIV prevention trial
}

\author{
Kristin M Wall ${ }^{1 *}$, Patrick S Sullivan ${ }^{1}$, David Kleinbaum ${ }^{1}$ and Rob Stephenson ${ }^{2}$
}

\begin{abstract}
Background: Intimate partner violence (IPV) and coercion have been associated with negative health outcomes, including increased HIV risk behaviors, among men who have sex with men (MSM). This is the first study to describe the prevalence and factors associated with experiencing IPV or coercion among US MSM dyads using the actor-partner interdependence model (APIM), an analytic framework to describe interdependent outcomes within dyads.
\end{abstract}

Methods: Among MSM couples enrolled as dyads in an HIV prevention randomized controlled trial (RCT), two outcomes are examined in this cross-sectional analysis: 1) the actor experiencing physical or sexual IPV from the study partner in the past 3-months and 2) the actor feeling coerced to participate in the RCT by the study partner. Two multilevel APIM logistic regression models evaluated the association between each outcome and actor, partner, and dyad-level factors.

Results: Of 190 individuals (95 MSM couples), 14 reported experiencing physical or sexual IPV from their study partner in the past 3 months (7.3\%) and 12 reported feeling coerced to participate in the RCT by their study partner (6.3\%). Results of multivariate APIM analyses indicated that reporting experienced IPV was associated $(p<0.1)$ with non-Black/African American actor race, lower actor education, and lower partner education. Reporting experienced coercion was associated $(p<0.1)$ with younger actor age and lower partner education.

Conclusions: These findings from an HIV prevention RCT for MSM show considerable levels of IPV experienced in the past 3-months and coercion to participate in the research study, indicating the need for screening tools and support services for these behaviors. The identification of factors associated with IPV and coercion demonstrate the importance of considering actor and partner effects, as well as dyadic-level effects, to improve development of screening tools and support services for these outcomes.

Keywords: Actor-partner interdependence model, Coercion, HIV, Intimate partner violence, MSM

\section{Background}

Of the roughly 50,000 new HIV infections occurring annually in the United States (US), CDC estimates 61\% occur among men who have sex with men (MSM), a group that accounts for $2 \%$ of the US population [1,2]. Due to disproportionally high HIV incidence among US MSM and the significantly increasing incidence rates observed among young, black MSM, MSM are an important

\footnotetext{
* Correspondence: kmwall@emory.edu

'Department of Epidemiology, Rollins School of Public Health and Laney Graduate School, Emory University, 1518 Clifton Road NE, 4th Floor, Atlanta, GA 30322, Georgia

Full list of author information is available at the end of the article
}

focus of CDCs High-Impact Prevention approach to HIV prevention [2-4]. Additionally, given that an estimated $68 \%$ of new transmissions among MSM occur in the context of main partnerships [5], more prevention efforts are focusing on male couples as a prevention point [6-10].

Recent studies have also shown MSM to be at increased risk of experiencing intimate partner violence (IPV) relative to other men, at similar or higher rates compared to heterosexual females, though varying operational definitions of the numerous types of IPV and the different study recall periods make comparisons difficult [11-13]. The National Violence Against Women Survey (NVAWS) defines physical IPV

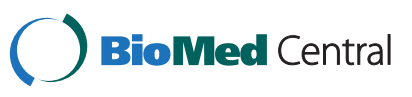


as physical attacks or threats of attacks within a relationship. NVAWS defines sexual IPV as oral, anal, or vaginal penetration completed or attempted through force or threat of force [14]. A nationally representative probability sample of 14,182 participants of the NVAWS estimated that physical IPV experienced during any past or current relationship occurred among 25\% of MSM, $8 \%$ of heterosexual males, and $21 \%$ of heterosexual females. This study estimated that experiences of sexual IPV occurred among $3 \%$ of MSM, $0.2 \%$ of heterosexual males, and $5 \%$ of heterosexual females [12]. These estimates are comparable with a probability-sample of 2,881 MSM from four US urban centers which found $22 \%$ of men experienced physical IPV (defined as being hit, pushed, shoved, kicked, or having something thrown at him) in the past 5 years, and $5 \%$ experienced sexual IPV (defined as being forced to have sex) in the past 5 years [13].

The reporting of experienced IPV by MSM has been strongly correlated with HIV/STI risk and more generally sexual risk-taking. Particularly, reporting experiencing of any form of IPV [15-18], of physical IPV [18], of sexual IPV $[18,19]$, and of psychological/emotional IPV [20] is correlated with recent unprotected anal intercourse (UAI). This underscores the potential role of IPV as a significant risk factor for HIV among MSM.

Estimates of coercion, broadly defined as attempting to control the thoughts/behaviors of others, are scarcer and operational definitions more varied. Some studies include coercive control in the definition of IPV, and current research indicates coercion may be a precursor to IPV $[21,22]$. The NVAWS defined controlling IPV as attempts to control the actions or thoughts of a partner and found estimates of lifetime experienced controlling IPV of $82 \%$ among MSM and $41 \%$ among both heterosexual men and women [12].

A limited number of cross-sectional studies using various recall periods for the definition of IPV have identified factors, primarily demographics and negative health correlates, associated with IPV experienced by MSM. A cross-sectional survey of 817 MSM in Chicago found lifetime experienced IPV (sexual, physical, or verbal) was associated with frequent (monthly or more often) alcohol intoxication, substance abuse, receptive or insertive UAI in the past 6 months, increased sero-discordant UAI, sexually transmitted infection (STI) diagnoses in the previous 2 years, depression, and lifetime mental health diagnoses [15]. A study among 521 South African MSM showed that experiencing physical IPV in the past year was associated with non-white race, higher levels of education, and reporting receptive or insertive UAI in the past year, while experiencing sexual IPV in the past year was associated with experiences of homophobia [23]. Another study among 2,881 US MSM reported physical IPV experienced in the past 5 years was associated with younger age, being HIV positive versus negative, and lower education, while sexual IPV experienced in the past
5 years was associated with younger age [13]. A multinational study of 2,368 gay men from six countries found that, while demographic characteristics associated with IPV varied widely across countries, reporting homophobic discrimination was associated with experienced physical or sexual IPV in the past 12 months in all countries [24]. Finally, in one of the first studies to examine dyadic-level characteristics and IPV, data from an online survey of 528 US MSM couples showed men reporting non-white race and decreased relationship satisfaction were more likely to report physical IPV experienced with their study partner. Men reporting lower education, HIV positive serostatus (positive for anti-HIV antibodies), and decreased perceived stigma about having a male partner were more likely to report sexual IPV experienced with their study partner [10].

We aim to add to this body of literature by describing the prevalence of experienced IPV and coercion to participate in a research study among MSM dyads enrolled in an HIV prevention study. One aspect of coercion, generally defined as behavioral or mental coercive control [12], is coercion to participate in research or obtain health services. We hypothesized that the prevalence of IPV and coercion would be similar to heterosexual women, and that education would be associated with IPV.

We evaluated the association between demographic factors and these outcomes using the actor-partner interdependence model (APIM). The APIM is an analytic framework to describe interdependent outcomes within dyads. In this model, an outcome for an individual within the dyad is measured in terms of their actor (self) characteristics, partner characteristics, and their dyadiclevel (shared) characteristics [25,26]. The APIM in an important tool for studying dyadic relationships and important outcomes that are influenced by the characteristics and actions of different members of a dyad, as well as measurements of their relationship to each other. Actor-partner effects among MSM have been evaluated for various health outcomes related to HIV risk including UAI within and outside the relationship [27], agreements about sex outside the relationship [28], and main and casual partner selection related to sero-sorting [7]. However, the actor-partner characteristics associated with IPV and coercion have yet to be studied among MSM.

\section{Methods}

\section{Recruitment and eligibility}

Male couples were recruited from the Atlanta area between 2010-2011 into a study of couples' voluntary HIV counseling and testing (CVCT) as described elsewhere [29,30]. Briefly, eligible couples were at least 18 years old, had been in a partnership for at least 3 months, reported willingness to complete a 3 month follow-up survey, had never received a diagnosis of HIV, and could complete study assessments 
in English. Eligible participants provided informed consent and were given $\$ 50$ for participation in the baseline survey and counseling session. This study was approved by Emory's Institutional Review Board.

\section{Study procedures}

Eligible and consenting participants separately answered a computer-administered baseline survey that collected demographic and couple characteristics, HIV testing history, sexual history, and several scales to measure aspects of couple functioning [6]. A survey administrator ensured that couples completed the survey at a sufficient physical distance so as to not influence one another. Two survey questions served as exclusionary criteria for randomization: history of experienced IPV (sexual or physical) in the past three months and feeling coerced by the study partner to test together. Couples in which either partner reported these exclusionary criteria were not considered eligible for randomization. These couples were informed that they would receive individual testing and were not told that one or both partners had reported IPV or coercion due to safety concerns.

\section{Exposures}

Exposures of interest in this analysis included individual (both actor and partner) level demographic variables (age, race/ethnicity, education, sexual orientation, serostatus, UAI with a man other than (and concurrent with) the main study partner in the past 3 months, and agreements about sex outside the relationship. Dyad-level relationship variables included duration of relationship (calculated as the average reported by both partners), UAI in past year with the main partner (reported by either partner), and dyadic differences in age, education, race, sexual orientation, and sexual relationship agreements. The arms of the RCT were not of primary interest in this analysis, and for our purposes the data are cross-sectional.

\section{Outcome variables}

Two primary outcomes were considered: 1) reporting a 3month history of experienced IPV, either sexual or physical, from the study partner and 2) reporting feeling coerced to participate in the RCT by the study partner. History of IPV was measured using the following questions which were modified from the Conflict Tactics Scale [31]: "In the past 3 months, has hit you, kicked you, or physically hurt you?" and "In the past 3 months has ever used force (hitting, holding down, or using a weapon) to make you have oral or anal sex?" Coercion by the study partner to participate in the RCT was measured using the following question: "Do you feel like research study?"

\section{Analyses}

To describe individual-level and dyadic-level exposures, counts and percentages for categorical exposure variables and medians and interquartile ranges (IQRs) for continuous variables were tabulated separately for the outcomes of interest. Two-sided p-values from Chi-square tests (or Fisher's Exacts tests) for categorical variables or median two-sample tests for continuous variables evaluated differences in individual-level and dyadic-level exposures separately for IPV and coercion. These descriptive analyses did not consider actor-partner effects.

The hypothesized association between actor, partner, and dyadic-level effects and each outcome is depicted schematically in Figure 1, adapted from Cook and Kenny [32]. Though not explicitly depicted in this schematic, dyads in this analysis are considered indistinguishable, meaning there is no meaningful way to distinguish outcomes between individual members of the dyad $[25,26]$.

To determine the actor-partner and dyadic-level effects associated with each outcome, the dataset was structured in a pairwise format $[25,26]$. Continuous variables were grand-mean centered and binary categorical variables were dummy coded. The pairwise intra-class correlation coefficient (PICC), a measure of the extent of dyadic interdependence, was calculated for each outcome. Multi-level APIM models were specified for this analysis as shown in Table 1.

Next, actor, partner, and dyadic-level effects were estimated following the 3-step multilevel modeling procedures for binary outcomes using an APIM framework as specified by McMahon et al., [33]. Briefly, PROC GENMOD was used to obtain initial values for the intercept and slope parameters using a generalized estimating equations approach (Appendix A1), PROC MIXED was used to determine initial values for the between-dyad variance (Appendix A2), and PROC NLMIXED was used to evaluate the random intercept model using these initial values (Appendix A3) (modified from McMahon et al., [33]).

The various analytical options used by McMahon et al., [33] were also utilized. The QPOINTS option defines the number of quadrature points needed for model convergence. The TECH $=$ NEWRAP option stipulates that the Newton-Raphson algorithm is used as the parameter estimation optimization technique. The PARMS statement specifies the values of the beta parameters and the variance of the random effects obtained from PROC GENMOD and PROC MIXED. We also performed data analysis using an analogous 1-step PROC GLIMMIX procedure as described in Flom et al. [34] for comparison (Appendix A4). To build the multivariate APIM models of reported IPV and coercion, the above procedures were first used to estimate the independent (crude bivariate) associations between actor, partner, 


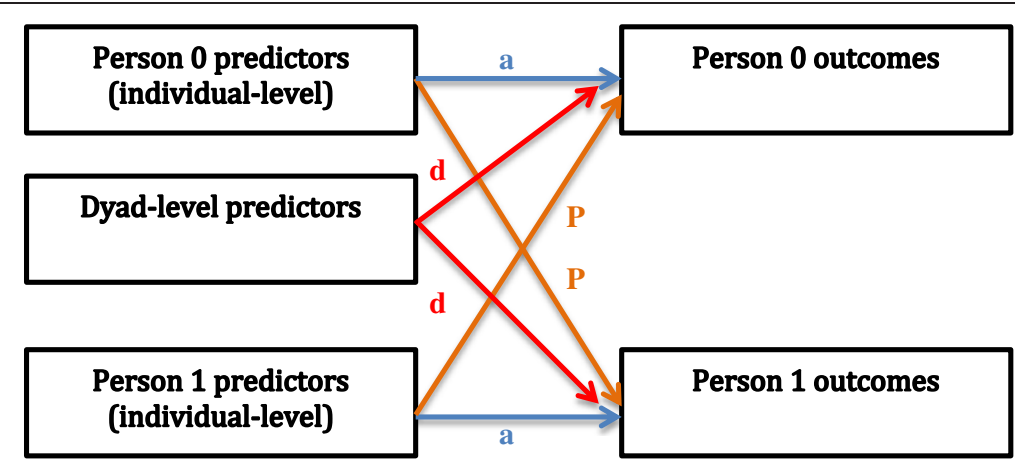

Figure 1 Schematic of the actor-partner interdependence model (APIM) framework, adapted from Cook \& Kenny, 2005 [32]. a, actor effects. p, partner effects. $\mathbf{d}$, dyad-level effects. Within-dyad residual errors between outcomes and predictors are not shown. Individual-level predictors (actor and partner): Age, race/ethnicity, education, sexual orientation, serostatus, unprotected anal intercourse with a man other than main partner in past 3 months, and agreements about sex outside the relationship. Dyad-level predictors: Duration of relationship with main partner (average of partner responses); unprotected anal intercourse in last year with main partner (reported by either partner); dyadic differences in age, education, race/ethnicity, sexual orientation, and agreements about sex outside the relationship. Outcomes: 1) IPV experienced from the study partner in the past three months, 2) coercion experienced from the study partner to participate in the study.

and dyadic-level factors and the outcomes of interest. Multivariate models were then built using backward selection procedures (using a cutoff of $\mathrm{p}<0.1$ for these exploratory analyses) to a model initially containing all exposures. Variables that were candidates for inclusion in the models were evaluated for multi-collinearity (cutoffs for multi-collinarity were taken as condition indices $>30$ and variance decomposition proportions $>0.5$ ). Odds ratios (OR) and 95\% confidence intervals (95\%CI) were calculated for all models. Data analysis was conducted with SAS v9.3 (Cary, NC).

\section{Results}

Individual-level factors independently associated with IPV and coercion

In this study of 190 individuals (95 couples), 14 individuals reported experiencing physical or sexual IPV from their study partner in the past 3 months (7.3\%). There were 12 individual reports of experienced physical IPV and 4 individual reports of experienced sexual IPV, with two individuals experiencing both behaviors. Twelve individuals reported experiencing coercion (6.3\%). Individuals from two couples reported experiencing both IPV and coercion.

Table 1 Specification of the multi-level actor-partner interdependence model

\begin{tabular}{|c|c|c|}
\hline Levels & Predictor labels & Predictors \\
\hline Individual actor and individual partner (i) & X_actor, X_partner & $\begin{array}{l}\text { Age, race/ethnicity, education, sexual orientation, serostatus, unprotected anal } \\
\text { intercourse with a man other than main partner in past } 3 \text { months, agreements } \\
\text { about sex outside the relationship }\end{array}$ \\
\hline Dyad (j) & Z & $\begin{array}{l}\text { Duration of relationship with main partner (average); unprotected anal intercourse } \\
\text { in last year with main partner; dyadic differences in age, education, race/ethnicity, } \\
\text { sexual orientation, and agreements about sex } \\
\text { outside the relationship }\end{array}$ \\
\hline
\end{tabular}

1. Individual level model: $\quad g^{-1}\left(m_{i j}\right)=\eta_{i j}=\beta_{0 j}+\beta_{1 j}\left(X_{-} \text {actor }\right)_{i j}+\beta_{2 j}\left(X_{-} \text {partner }\right)_{i j}$

Individual level residual term is omitted because its variance is assumed fixed

$\boldsymbol{\eta}_{\mathbf{i j}}$ is the log odds of the outcome

$\boldsymbol{\beta}_{\mathbf{0}}$ is the within-dyad intercept in dyad $\mathbf{j}$

$\boldsymbol{\beta}_{\mathbf{1 j}}$ is the slope of $\eta_{i j}$ on $x_{i j}$ in dyad $j$

2. Dyad level model: $\quad \beta_{0 j}=\gamma_{00}+\gamma_{01}(Z)_{j}+u_{o j}, \beta_{1 j}=\gamma_{10}, \beta_{2 j}=\gamma_{20}$

Dyad level slopes are fixed

$\mathbf{u}_{\mathbf{0} \mathbf{j}}$, the random intercept, is the only random effect

$\mathbf{Y}_{\mathbf{o o}}$ is the average intercept across dyads

3. Final model: $\quad \eta_{i j}=\gamma_{00}+\gamma_{01}(Z)_{j}+\gamma_{10}\left(X_{-} \text {actor }\right)_{i j}+\gamma_{20}\left(X_{-} \text {partner }\right)_{i j}+u_{o j}$, 
Within one couple, both partners experienced coercion. The magnitude and direction of the associations between white/Caucasian race $(n=30)$ and the outcomes, and other races $(n=19)$ and the outcomes, were similar. These race categories were grouped $(\mathrm{n}=49)$ for analysis due to small numbers among the coercion outcome.

In bivariate analyses, individuals reporting IPV were older on median than individuals not reporting IPV (33.5 years versus 30.0 years, $\mathrm{p}=0.01$ ). Individuals who reported having a high school/GED education or less were more likely to report IPV relative to individuals with some post-high school education $(13 \%$ versus $2 \%, \mathrm{p}=0.004)$ (Table 2$)$.

\section{Dyad-level factors independently associated with IPV and coercion}

In bivariate analyses, couples reporting coercion had a relatively larger dyadic-difference in median age (6.0 years versus 4.0 years, $\mathrm{p}=0.02$ ) (Table 3 ).

\section{Actor-partner and dyad-level factors associated with IPV} The estimates obtained from implementing the 3-step analysis method described (PROC GENMOD, MIXED, and NLMIXED) were very similar to those obtained using the 1-step PROC GLIMMIX procedure for all models. The 3-step method results are presented for all analyses as this method produces an approximation to the likelihood with a log-likelihood fit statistic and is thought to produce more valid results [34].

In multivariate analysis, non-black/African American actor race $(\mathrm{p}=0.02)$, actor high school/GED education or less $(\mathrm{p}=0.06)$, and partner high school/GED education or less $(\mathrm{p}=0.06)$ were associated with experiencing IPV (Table 4). No collinearity was detected between model variables and no significant interaction terms were discovered.

\section{Actor-partner and dyad-level factors associated} with coercion

In multivariate analysis, younger actor age $(\mathrm{p}=0.098)$ and partner high school/GED education or less $(\mathrm{p}=0.09)$ were associated were associated with experiencing coercion (Table 5). No collinearity was detected between model variables and no significant interaction terms were discovered.

Table 2 Individual-level demographic characteristics associated with experiencing IPV or coercion

\begin{tabular}{|c|c|c|c|c|c|c|c|c|c|c|c|c|}
\hline & \multicolumn{2}{|c|}{$\begin{array}{l}\text { Total } \\
(\mathrm{N}=190)\end{array}$} & \multicolumn{2}{|c|}{$\begin{array}{c}\text { No } \\
\text { experienced } \\
\text { IPV }(\mathrm{N}=176)\end{array}$} & \multicolumn{2}{|c|}{$\begin{array}{l}\text { Experienced } \\
\text { IPV }(\mathrm{N}=14)\end{array}$} & \multirow[t]{2}{*}{ p-value* } & \multicolumn{2}{|c|}{$\begin{array}{l}\text { No experienced } \\
\text { coercion }(N=178)\end{array}$} & \multicolumn{2}{|c|}{$\begin{array}{c}\text { Experienced } \\
\text { coercion }(N=12)\end{array}$} & \multirow[t]{2}{*}{ p-value* } \\
\hline & $\mathbf{N}$ & col\% & $\mathbf{N}$ & row $\%$ & $\mathbf{N}$ & row $\%$ & & $\mathbf{N}$ & row\% & $\mathrm{N}$ & row $\%$ & \\
\hline Age, median, IQR (years) & 30.0 & 14.0 & 30.0 & 15.0 & 33.5 & 12.0 & 0.01 & 30.0 & 15.0 & 28.0 & 15.0 & 0.406 \\
\hline Race/ethnicity & & & & & & & 0.20 & & & & & 0.07 \\
\hline Black/African American & 137 & $74 \%$ & 129 & $94 \%$ & 8 & $6 \%$ & & 126 & $92 \%$ & 11 & $8 \%$ & \\
\hline Other & 49 & $26 \%$ & 43 & $88 \%$ & 6 & $12 \%$ & & 49 & $100 \%$ & 0 & $0 \%$ & \\
\hline Education & & & & & & & 0.004 & & & & & 0.48 \\
\hline Some education post-high school & 98 & $52 \%$ & 96 & $98 \%$ & 2 & $2 \%$ & & 93 & $95 \%$ & 5 & $5 \%$ & \\
\hline High school, GED, or less & 92 & $48 \%$ & 80 & $87 \%$ & 12 & $13 \%$ & & 85 & $92 \%$ & 7 & $8 \%$ & \\
\hline Sexual orientation & & & & & & & 1.00 & & & & & 0.36 \\
\hline Homosexual/gay & 116 & $63 \%$ & 108 & $93 \%$ & 8 & $7 \%$ & & 110 & $95 \%$ & 6 & $5 \%$ & \\
\hline Bisexual/other & 68 & $37 \%$ & 63 & $93 \%$ & 5 & $7 \%$ & & 62 & $91 \%$ & 6 & $9 \%$ & \\
\hline Serostatus & & & & & & & 1.00 & & & & & 1.00 \\
\hline HIV positive & 20 & $11 \%$ & 19 & $95 \%$ & 1 & $5 \%$ & & 19 & $95 \%$ & 1 & $5 \%$ & \\
\hline HIV negative & 170 & $89 \%$ & 157 & $92 \%$ & 13 & $8 \%$ & & 159 & $94 \%$ & 11 & $6 \%$ & \\
\hline $\begin{array}{l}\text { UAl with an outside (and concurrent } \\
\text { with main) partner in past } 3 \text { months }\end{array}$ & & & & & & & 1.00 & & & & & 0.46 \\
\hline Yes & 38 & $21 \%$ & 36 & $95 \%$ & 2 & $5 \%$ & & 37 & $97 \%$ & 1 & $3 \%$ & \\
\hline No & 145 & $79 \%$ & 135 & $93 \%$ & 10 & $7 \%$ & & 135 & $93 \%$ & 10 & $7 \%$ & \\
\hline $\begin{array}{l}\text { Agreements about sex outside } \\
\text { the relationship }\end{array}$ & & & & & & & 0.12 & & & & & 0.42 \\
\hline Monogamy & 105 & $56 \%$ & 100 & $95 \%$ & 5 & $5 \%$ & & 97 & $92 \%$ & 8 & $8 \%$ & \\
\hline Other (Outside sex, no agreement) & 84 & $44 \%$ & 75 & $89 \%$ & 9 & $11 \%$ & & 80 & $95 \%$ & 4 & $5 \%$ & \\
\hline
\end{tabular}

*Two-sided p-values from Chi-square tests or Fisher's Exacts tests (categorical variables) or Median two-sample tests (continuous variables). Cells may not add to total due to missing values.

GED: general educational development; IPV: intimate partner violence; IQR: interquartile range; UAI: unprotected anal intercourse. 
Table 3 Dyad-level demographic characteristics associated with experiencing IPV or coercion

\begin{tabular}{|c|c|c|c|c|c|c|c|c|c|c|c|c|}
\hline & \multicolumn{2}{|c|}{$\begin{array}{l}\text { Total } \\
(\mathrm{N}=95)\end{array}$} & \multicolumn{2}{|c|}{$\begin{array}{c}\text { No } \\
\text { experienced } \\
\text { IPV }(\mathrm{N}=81) \\
\end{array}$} & \multicolumn{2}{|c|}{$\begin{array}{l}\text { Experienced } \\
\text { IPV }(\mathrm{N}=14)\end{array}$} & \multirow[t]{2}{*}{ p-value* } & \multicolumn{2}{|c|}{$\begin{array}{l}\text { No experienced } \\
\text { coercion }(\mathrm{N}=84)\end{array}$} & \multicolumn{2}{|c|}{$\begin{array}{c}\text { Experienced } \\
\text { coercion }(\mathrm{N}=11)\end{array}$} & \multirow[t]{2}{*}{$p$-value* } \\
\hline & $\mathrm{N}$ & col\% & $\mathbf{N}$ & row\% & $\mathbf{N}$ & row\% & & $\mathbf{N}$ & row\% & $\mathbf{N}$ & row\% & \\
\hline $\begin{array}{l}\text { Duration of relationship with main } \\
\text { partner, median, IQR (months) } \\
\text { (average reported by both partners) }\end{array}$ & 14.0 & 17.3 & 13.4 & 16.0 & 22.1 & 21.7 & 0.08 & 13.9 & 17.0 & 14.4 & 24.5 & 0.35 \\
\hline $\begin{array}{l}\text { UAI with main partner in past year } \\
\text { (reported by either partner) }\end{array}$ & & & & & & & 0.53 & & & & & 0.73 \\
\hline Yes & 58 & $65 \%$ & 48 & $83 \%$ & 10 & $17 \%$ & & 52 & $90 \%$ & 6 & $10 \%$ & \\
\hline No & 31 & $35 \%$ & 28 & $90 \%$ & 3 & $10 \%$ & & 27 & $87 \%$ & 4 & $13 \%$ & \\
\hline $\begin{array}{l}\text { Difference in age, median, } \\
\text { IQR (years) }\end{array}$ & 4.0 & 6.0 & 4.0 & 6.0 & 4.5 & 4.0 & 0.97 & 4.0 & 5.5 & 6.0 & 6.0 & 0.02 \\
\hline Difference in education & & & & & & & 0.34 & & & & & 1.00 \\
\hline Report same & 69 & $73 \%$ & 57 & $83 \%$ & 12 & $17 \%$ & & 61 & $88 \%$ & 8 & $12 \%$ & \\
\hline Report different & 26 & $27 \%$ & 24 & $92 \%$ & 2 & $8 \%$ & & 23 & $88 \%$ & 3 & $12 \%$ & \\
\hline Difference in race & & & & & & & 1.00 & & & & & 0.67 \\
\hline Report same (both black, white, other) & 76 & $84 \%$ & 64 & $84 \%$ & 12 & $16 \%$ & & 68 & $89 \%$ & 8 & $11 \%$ & \\
\hline Report different & 15 & $16 \%$ & 13 & $87 \%$ & 2 & $13 \%$ & & 13 & $87 \%$ & 2 & $13 \%$ & \\
\hline Difference in orientation & & & & & & & 0.35 & & & & & 1.00 \\
\hline Report same & 56 & $63 \%$ & 50 & $89 \%$ & 6 & $11 \%$ & & 49 & $88 \%$ & 7 & $13 \%$ & \\
\hline Report different & 33 & $37 \%$ & 27 & $82 \%$ & 6 & $18 \%$ & & 29 & $88 \%$ & 4 & $12 \%$ & \\
\hline Difference in agreements & & & & & & & 0.80 & & & & & 0.46 \\
\hline Report same & 50 & $53 \%$ & 43 & $86 \%$ & 7 & $14 \%$ & & 43 & $86 \%$ & 7 & $14 \%$ & \\
\hline Report different & 44 & $47 \%$ & 37 & $84 \%$ & 7 & $16 \%$ & & 40 & $91 \%$ & 4 & $9 \%$ & \\
\hline
\end{tabular}

Cells may not add to total due to missing values.

IPV: intimate partner violence; IQR: interquartile range; UAI: unprotected anal intercourse.

*Two-sided p-values from Chi-square tests or Fisher's Exacts tests (categorical variables) or Median two-sample tests (continuous variables).

\section{Discussion}

In this analysis of MSM participating in an HIV prevention study as dyads, our estimates of physical or sexual IPV in the previous 3 months (7\% prevalence) and experienced coercion to participate in the study (6\% prevalence) were similar to studies measuring more recent IPV among MSM. A study of MSM from 6 countries found $5.8 \%$ of US MSM reported experiencing physical IPV in the past year, and $4.5 \%$ reported experiencing sexual IPV in the past year [24]. To our knowledge, there are no large population-based estimates of coercion as defined here among MSM dyads.

There are currently no other published studies examining both the actor-partner effects in addition to the shared dyad-level characteristics associated with these outcomes among MSM. Evaluating actor-partner effects within the APIM framework is advantageous because it considers how one partner's exposures may influence the other partner's outcomes. These nuanced associations can be missed when looking at data at the individual-level only. For example, race was not significantly associated with experiencing IPV at the individual-level but was a significant actor effect in the multivariate actor-partner model.

\section{Actor-partner effects associated with experienced IPV}

The actor reporting non-black/African American race was associated with experiencing IPV in the past 3 months relative to the actor being black/African American. Since our sample was predominately black/African American, we were not able to evaluate race differences in more depth. The existing literature regarding race and IPV among MSM is varied and conflicting - for example, in the previously described study of 528 US MSM, non-white race was found to be significantly associated with experiencing physical IPV [10], while the results of the study of 2,881 US MSM indicated that race was not associated with reporting physical or sexual IPV [13]. These differences highlight a recurring theme in the current literature: demographic characteristics hypothesized to be associated with IPV do not translate to every MSM population, especially in the multinational study by Finnernan et al. [24]. For example, we did not find an association between age and experiences of recent IPV, and again results are varied in the current literature - some studies indicate younger age is associated with experienced physical or sexual IPV among MSM [13,24], while other studies among MSM observed no association with age 
Table 4 Actor-partner interdependence model of factors associated with experiencing IPV

\begin{tabular}{|c|c|c|c|c|c|c|c|c|}
\hline ACTOR VARIABLES & Crude OR & \multicolumn{2}{|c|}{$(90 \% \mathrm{Cl})$} & \multirow{2}{*}{$\begin{array}{c}\text { p-value } \\
0.09\end{array}$} & Adjusted OR & \multicolumn{2}{|c|}{$(90 \% \mathrm{Cl})$} & $\mathrm{p}$-value \\
\hline Age, per year increase & 1.05 & 1.00 & 1.09 & & & & & \\
\hline \multicolumn{9}{|l|}{ Race/ethnicity } \\
\hline Black/African American & ref & & & & & & & \\
\hline Other & 2.25 & 0.88 & 5.77 & 0.16 & 4.25 & 1.49 & 12.12 & 0.024 \\
\hline \multicolumn{9}{|l|}{ Education } \\
\hline Some education post-high school & ref & & & & & & & \\
\hline High school, GED, or less & 7.20 & 1.98 & 26.18 & 0.013 & 5.01 & 1.23 & 20.45 & 0.06 \\
\hline \multicolumn{9}{|l|}{ Sexual orientation } \\
\hline Homosexual/gay & ref & & & & & & & \\
\hline Bisexual/other & 1.07 & 0.40 & 2.86 & 0.91 & & & & \\
\hline \multicolumn{9}{|l|}{ Serostatus } \\
\hline HIV positive & ref & & & & & & & \\
\hline HIV negative & 1.57 & 0.27 & 9.21 & 0.67 & & & & \\
\hline \multicolumn{9}{|c|}{$\begin{array}{l}\text { UAl with a man other than (and concurrent with) } \\
\text { main partner in past } 3 \text { months }\end{array}$} \\
\hline Yes & ref & & & & & & & \\
\hline No & 1.33 & 0.36 & 5.00 & 0.72 & & & & \\
\hline \multicolumn{9}{|c|}{ Agreements about sex outside the relationship } \\
\hline Monogamy & ref & & & & & & & \\
\hline Other (Outside sex, no agreements) & 2.40 & 0.92 & 6.26 & 0.13 & & & & \\
\hline \multicolumn{9}{|l|}{ PARTNER VARIABLES } \\
\hline Age, per year increase & 1.05 & 1.01 & 1.10 & 0.05 & & & & \\
\hline \multicolumn{9}{|l|}{ Race/ethnicity } \\
\hline Black/African American & ref & & & & & & & \\
\hline Other & 1.13 & 0.41 & 3.14 & 0.85 & & & & \\
\hline \multicolumn{9}{|l|}{ Education } \\
\hline Some education post-high school & ref & & & & & & & \\
\hline High school, GED, or less & 7.20 & 1.98 & 26.18 & 0.01 & 5.14 & 1.26 & 20.92 & 0.056 \\
\hline \multicolumn{9}{|l|}{ Sexual orientation } \\
\hline Homosexual/gay & ref & & & & & & & \\
\hline Bisexual/other & 1.51 & 0.58 & 3.93 & 0.48 & & & & \\
\hline \multicolumn{9}{|l|}{ Serostatus } \\
\hline HIV positive & ref & & & & & & & \\
\hline HIV negative & 1.57 & 0.27 & 9.21 & 0.67 & & & & \\
\hline \multicolumn{9}{|c|}{$\begin{array}{l}\text { UAI with a man other than (and concurrent with) } \\
\text { main partner in past } 3 \text { months }\end{array}$} \\
\hline Yes & 1.78 & 0.62 & 5.06 & 0.36 & & & & \\
\hline No & ref & & & & & & & \\
\hline \multicolumn{9}{|c|}{ Agreements about sex outside the relationship } \\
\hline Monogamy & ref & & & & & & & \\
\hline Other (Outside sex, no agreements) & 1.74 & 0.68 & 4.40 & 0.33 & & & & \\
\hline
\end{tabular}


Table 4 Actor-partner interdependence model of factors associated with experiencing IPV (Continued)

\begin{tabular}{|c|c|c|c|c|}
\hline DYAD-LEVEL VARIABLES & & & & \\
\hline $\begin{array}{l}\text { Duration of relationship with main partner (average reported by } \\
\text { both partners, per year increase) }\end{array}$ & 1.01 & 1.00 & 1.03 & 0.15 \\
\hline UAI with main partner in past year (reported by either partner) & & & & \\
\hline Yes & 1.86 & 0.60 & 5.71 & 0.36 \\
\hline No & ref & & & \\
\hline Difference in age (per year decrease) & 1.02 & 0.93 & 1.13 & 0.69 \\
\hline Difference in education & & & & \\
\hline Report same & 2.36 & 0.65 & 8.70 & 0.28 \\
\hline Report different & ref & & & \\
\hline Difference in race & & & & \\
\hline Report same (both black, white, other) & 1.20 & 0.32 & 4.46 & 0.82 \\
\hline Report different & ref & & & \\
\hline Difference in orientation & & & & \\
\hline Report same & ref & & & \\
\hline Report different & 1.77 & 0.65 & 4.78 & 0.35 \\
\hline Difference in agreements & & & & \\
\hline Report same & ref & & & \\
\hline Report different & 1.15 & 0.46 & 2.89 & 0.80 \\
\hline
\end{tabular}

GED: general educational development; IPV: intimate partner violence; UAl: unprotected anal intercourse.

[23,35]. Younger age is a classic risk factor for IPV experienced by heterosexual women, seemingly linked to the fact men tend to become less violent with age [36], but this association does not appear consistent across MSM populations.

Lower education was associated with reporting experienced IPV in the past 3 months in this study. Many investigations indicate a link between lower education and violence among MSM [10,13,35], as lower education may be associated with decreased access to economic, social, and health resources thereby increasing vulnerability. However, in the current study we further show that both actor and partner educational level have an effect.

\section{Actor-partner effects associated with experienced coercion}

The actor-partner and dyadic-level factors associated with experiencing coercion to participate in the study were younger actor age and lower partner education. While we are unaware of similar investigations of factors associated with coercion to participate in research studies between MSM couples for comparison, younger age and lower education have been associated with controlling IPV [12], and we hypothesize that the younger age of the actor creates a power dynamic making them more susceptible to experiencing coercive control. A study by Greenwood et al. [13], which found a role for age in all forms of IPV, hypothesized that older persons may be better able to access resources and protection's than younger people, or that younger people may be easier to influence [13].

\section{Screening for IPV and coercion in research and} programmatic settings

IPV and coercion were screened for in this RCT in order to nonrandomly allocate couples reporting these behaviors to receive individual HIV testing, because the effect of the CVCT service on these behaviors is currently unclear. Additionally, in a research setting, coercion to participate in a study represents a threat to human subjects and bias study results. In a programmatic setting, screening for coercion to participate in programs designed for male-male couples is important to ensure that services are delivered to clients who both desire and have independently chosen to receive the service.

More generally, in couples-focused research or programmatic settings, screening for IPV among MSM couples is an important opportunity for referrals for IPV support services. Importantly, evidence suggests coercive control may be an upstream behavior leading to IPV $[21,22]$ further motivating the rationale for screening for coercion in order to refer persons reporting this behavior for support services [22].

\section{Screening tool and support service development}

IPV screening tools do not currently have well-established psychometric soundness for use among MSM, the sensitivities and specificities between current screening tools vary greatly, few consider coercion a separate behavior, and the most common screening tools have been evaluated in relatively few studies among primarily heterosexuals 
Table 5 Actor-partner interdependence model of factors associated with experiencing coercion

\begin{tabular}{|c|c|c|c|c|c|c|c|}
\hline & Crude OR & $\left(90^{\circ}\right.$ & $\% \mathrm{Cl})$ & p-value & Adjusted OR & $(90 \% \mathrm{Cl})$ & p-value \\
\hline \multicolumn{8}{|l|}{ ACTOR VARIABLES } \\
\hline Age, per year decrease & 1.05 & 0.99 & 1.11 & 0.21 & 1.06 & $1.00 \quad 1.13$ & 0.098 \\
\hline \multicolumn{8}{|l|}{ Race/ethnicity } \\
\hline Black/African American & $\mathrm{n} / \mathrm{a}$ & & & & & & \\
\hline Other & & & & & & & \\
\hline
\end{tabular}

Education

Some education post-high school

High school, GED, or less

\section{Sexual orientation}

Homosexual/gay

Bisexual/other

\section{Serostatus}

$$
\begin{aligned}
& \text { HIV positive } \\
& \text { HIV negative }
\end{aligned}
$$

UAI with a man other than (and concurrent with) main partner in past 3 months

$$
\text { Yes }
$$

No

Agreements about sex outside the relationship

Monogamy

Other (Outside sex, no agreements)

\section{PARTNER VARIABLES}

Age, per year decrease

Race/ethnicity

Black/African American

Other

\section{Education}

Some education post-high school

High school, GED, or less

\section{Sexual orientation}

Homosexual/gay

Bisexual/other

\section{Serostatus}

$$
\begin{aligned}
& \text { HIV positive } \\
& \text { HIV negative }
\end{aligned}
$$

UAI with a man other than (and concurrent with) main partner in past 3 months

$$
\text { Yes }
$$$$
\text { No }
$$

Agreements about sex outside the relationship

$$
\begin{aligned}
& \text { Monogamy } \\
& \text { Other (Outside sex, no agreements) }
\end{aligned}
$$

ref

$\begin{array}{llll}1.53 & 0.56 & 4.18 & 0.48\end{array}$

ref

$\begin{array}{llll}1.77 & 0.66 & 4.79 & 0.34\end{array}$

ref

$$
0.22 \quad 7.78
$$

$$
2.74
$$$$
0.47 \quad 16.05
$$

ref

ref

ref 
Table 5 Actor-partner interdependence model of factors associated with experiencing coercion (Continued)

\begin{tabular}{|c|c|c|c|c|}
\hline \multicolumn{5}{|l|}{ DYAD-LEVEL VARIABLES } \\
\hline $\begin{array}{l}\text { Duration of relationship with main partner (average reported by } \\
\text { both partners, per year increase) }\end{array}$ & 1.01 & 1.00 & 1.03 & 0.46 \\
\hline \multicolumn{5}{|l|}{ UAI with main partner in past year (reported by either partner) } \\
\hline Yes & ref & & & \\
\hline No & 1.61 & 0.57 & 4.56 & 0.45 \\
\hline Difference in age (per year increase) & 1.01 & 0.92 & 1.11 & 0.87 \\
\hline \multicolumn{5}{|l|}{ Difference in education } \\
\hline Report same & 1.13 & 0.36 & 3.56 & 0.86 \\
\hline Report different & ref & & & \\
\hline \multicolumn{5}{|l|}{ Difference in race } \\
\hline Report same (both black, white, other) & ref & & & \\
\hline Report different & 1.14 & 0.30 & 4.34 & 0.88 \\
\hline \multicolumn{5}{|l|}{ Difference in orientation } \\
\hline Report same & 1.19 & 0.42 & 3.41 & 0.78 \\
\hline Report different & ref & & & \\
\hline \multicolumn{5}{|l|}{ Difference in agreements } \\
\hline Report same & 1.25 & 0.46 & 3.41 & 0.71 \\
\hline Report different & ref & & & \\
\hline
\end{tabular}

GED: general educational development; UAI: unprotected anal intercourse.

[21,22,37]. IPV support services for MSM are also inadequate - awareness of these issues among MSM is low, many US domestic violence services do not serve men, and IPV victims from same-sex relationships are not provided civil protections in several states [12,38]. This preliminary understanding actor-partner effects and dyadic differences related to IPV and coercion suggests that screening tools and support services can benefit from an understanding of both actor and partner effects, and that they may benefit from targeting younger, less educated MSM. Though our findings are preliminary, we believe that other, larger studies designed to better understanding these associations should be conducted to inform the development of screening tools and support services.

\section{Limitations}

Several limitations to this study warrant consideration. The small sample size and exploratory nature of our analysis $(\mathrm{p}<0.1)$ did not allow for a deeper investigation of several associations, especially investigation of racial/ethnic differences and these outcomes, or the differences between physical and sexual IPV. Since IPV was not the primary study outcome, it was assessed using only two modified items from the Conflict Tactics Scale. If we had assessed IPV more comprehensively using the entire scale, we likely would have discovered more cases on IPV. Selection bias affecting who decided to participate in the study and who decided to answer the questions about IPV and coercion could limit the generalizability of these findings to MSM in couples who were interested in being tested together for HIV. Although measures were taken to ensure confidentiality in reporting IPV and coercion, misclassification of sensitive relationship outcomes is common $[39,40]$ and may have affected the validity of our findings, likely underestimating the true prevalence of IPV and coercion. Additionally, given that these data are cross-sectional, we were only able to evaluate associations and not possible causal mechanisms. Longitudinal data exploring the causal associations between couple characteristics and IPV and coercion among MSM are needed.

Because this study was not designed or powered to detect differences in these outcomes, the analyses are exploratory and results should be interpreted with caution.

However, this study represents the first steps toward understanding the main actor-partner effects and dyadic characteristics related to IPV and coercion. This novel use of the APIM employing systematic model building techniques would benefit from being applied to larger sample sizes and more diverse populations of MSM couples with consideration of the frequency and severity of IPV and coercion. Other exposures associated with IPV and coercion in previous studies also need to be considered in terms of actor and partner effects including substance abuse $[15,41]$, homophobic discrimination and internalized homophobia [23,24,35], experiences of homophobia [23,24], history of violence [35], relationship concurrency, and perceived stigma [10]. 


\section{Conclusions}

Understanding the prevalence and factors associated with IPV and coercion among MSM increases awareness of these issues and the need for better screening tools and support services. Based on the results of this study and the current literature, we recommend future studies evaluate actor, partner, and dyadic-level predictors of IPV and coercion toward the goal of improving screening tools and support services for IPV and coercion among MSM couples.

\section{Appendix}

A1. Obtain initial values for the intercept and slope parameters:

$$
\begin{aligned}
\text { proc genmod data }= & \text { dataset descending; } \\
& \text { class dyad } \\
\text { model outcome }= & X_{- \text {partner }} X_{- \text {actor }} Z / \text { dist }=\text { bin link }=\text { logit } ; \\
\text { repeated subject }= & \text { dyad } / \text { type }=u n \\
\text { run } ; &
\end{aligned}
$$

A2. Determine initial values for the between-dyad variance:

$$
\begin{gathered}
\text { proc mixed data }=\text { dataset method }=\text { reml; } \\
\text { class dyad; } \\
\text { model outcome }=X_{- \text {partner }} X_{- \text {actor }} Z / \text { solution; } \\
\text { random intercept } / \text { subject }=d y a d ; \\
\text { run } ;
\end{gathered}
$$

A3. Evaluate the random intercept model using the initial values from steps A1 and A2:

$$
\begin{aligned}
\text { proc nlmixed data }= & \text { dataset qpoints }=20 \text { tech }=\text { newrap; } \\
& \text { parms beta } 0=x 0 \text { beta } 1=x 1 \text { beta } 2 \\
= & x 2 \text { beta } 3=x 3 \text { s } 2 u=x 4 ; \\
& \text { eta }=\text { beta } 0+\text { beta } 1 * X \_ \text {actor } \\
& + \text { beta } 2 * X \_ \text {partner }+ \text { beta } 3 * Z+u ; \\
& \text { mu=exp }(\text { eta }) /(1+\exp (\text { eta })) ; \\
& \text { model outcome } \sim \text { binary }(\text { mu }) ; \\
& \text { random } u_{\sim} \text { normal }(0, s 2 u) \text { subject } \\
= & \text { dyad } \\
\text { run; } &
\end{aligned}
$$

A4. One step procedure to obtain beta estimates:

$$
\begin{aligned}
\text { proc glimmix data }= & \text { dataset } ; \\
& \text { class dyad; } \\
& \text { model outcome }=X_{- \text {actor }} X_{- \text {parnter }} Z \\
& \text { / } \text { solution link }=\text { logit dist }=\text { binomial; } \\
& \text { random intercept } / \text { subject }=\text { dyad type } \\
= & \text { un gcorr } ; \\
& \text { run } ;
\end{aligned}
$$

\section{Abbreviations}

APIM: Actor-partner interdependence model; CVCT: Couples' voluntary HIV counseling and testing; IPV: Intimate partner violence; IQR: Interquartile range; MSM: Men who have sex with men; NVAWS: National violence against women survey; RCT: Randomized controlled trial; UAl: Unprotected anal intercourse.

\section{Competing interests}

The authors declare that they have no competing interests.

\section{Authors' contributions}

KW made substantial contributions to the analysis and interpretation of data, drafting the article and revising it critically for important intellectual content, and gave final approval of the version to be published. PS made substantial contributions to study conception and design, acquisition of data, was involved in drafting the manuscript or revising it critically for important intellectual content, and gave final approval of the version to be published. DK made substantial contributions to the analysis and interpretation of data, revising the article critically for important intellectual content, and gave final approval of the version to be published. RS made substantial contributions to study conception and design, acquisition of data, was involved in drafting the manuscript or revising it critically for important intellectual content, and gave final approval of the version to be published. All authors read and approved the final manuscript.

\section{Acknowledgements}

We would like to acknowledge Jason Mitchell for his insights on applying the APIM model to this dataset. We would also like to acknowledge The Emory Center for AIDS Research (CFAR P30 Al050409).

\section{Funding sources}

National Institutes of Health (R34-MH086331) and The Emory Center for AIDS Research (P30-Al050409).

\section{Author details}

'Department of Epidemiology, Rollins School of Public Health and Laney Graduate School, Emory University, 1518 Clifton Road NE, 4th Floor, Atlanta, GA 30322, Georgia. ${ }^{2}$ Hubert Department of Global Health, Rollins School of Public Health and Laney Graduate School, Emory University, Atlanta, Georgia.

Received: 5 March 2013 Accepted: 17 February 2014

Published: 28 February 2014

\section{References}

1. Purcell DW, Johnson C, Lansky A, Prejean J, Stein R, Denning P, Gaul Z Weinstock H, Su J, Crepaz N: Estimate of number of MSM in the United States and MSM's rates of HIV and syphilis. Abstract 22896. In National STD Prevention Conference, March 8-11. Atlanta, GA: CDC; 2010.

2. Prejean J, Song R, Hernandez A, Ziebell R, Green T, Walker F, Lin LS, An Q, Mermin J, Lansky A, Hall HI, HIV Incidence Surveillance Group: Estimated HIV incidence in the United States, 2006-2009. PLOS ONE 2011, 6(8):e17502

3. Mermin J: The Science and Practice of HIV Prevention in the United States. Paper \#19. In 18th Conference on Retroviruses and Opportunistic Infections, February 27-March 2. Boston, MA: IAS-USA/CROI; 2011.

4. CDC: High-Impact HIV Prevention. Atlanta, GA: Centers for Disease Control and Prevention, National Center for HIV/AIDS, Viral Hepatitis, STD, and TB Prevention; 2011.

5. Sullivan PS, Salazar L, Buchbinder S, Sanchez TH: Estimating the proportion of HIV transmissions from main sex partners among men who have sex with men in five US cities. AIDS 2009, 23(9):1153-1162.

6. Salazar LF, Stephenson RB, Sullivan PS, Tarver R: Development and validation of HIV-related dyadic measures for men who have sex with men. J Sex Res 2011. Epub ahead of print.

7. Eaton LA, West TV, Kenny DA, Kalichman SC: HIV transmission risk among HIV seroconcordant and serodiscordant couples: dyadic processes of partner selection. AIDS Behav 2009, 13(2):185-195.

8. Mitchell JW, Harvey SM, Champeau D, Moskowitz DA, Seal DW: Relationship factors associated with gay male couples' concordance on aspects of their sexual agreements: establishment, type, and adherence. AIDS Behav 2012, 16(6):1560-1569.

9. Mitchell JW, Petroll AE: HIV testing rates and factors associated with recent HIV testing among male couples. Sex Transm Dis 2012, 39(5):379-381.

10. Stephenson R, Rentsch C, Salazar LF, Sullivan PS: Dyadic characteristics and intimate partner violence among men who have sex with men. West $J$ Emerg Med 2011, 12(3):324-332. 
11. Tjaden $\mathrm{P}$, Thoennes $\mathrm{N}$, Allison CJ: Comparing violence over the life span in samples of same-sex and opposite-sex cohabitants. Violence Vict 1999, 14(4):413-425

12. Messinger AM: Invisible victims: same-sex IPV in the national violence against women survey. J Interpers Violence 2011, 26(11):2228-2243.

13. Greenwood GL, Relf MV, Huang B, Pollack LM, Canchola JA, Catania JA Battering victimization among a probability-based sample of men who have sex with men. Am J Public Health 2002, 92(12):1964-1969.

14. Tjaden $P$, Thoennes $N$ : Prevalence and consequences of male-to-female and female-to-male partner violence as measured by the national violence against women survey. Violence Against Women 2000, 6:142-161.

15. Houston E, McKirnan DJ: Intimate partner abuse among gay and bisexual men: risk correlates and health outcomes. J Urban Health 2007, 84(5):681-690.

16. Stall R, Mills TC, Williamson J, Hart T, Greenwood G, Paul J, Pollack L, Binson D, Osmond D, Catania JA: Association of co-occurring psychosocial health problems and increased vulnerability to HIV/AIDS among urban men who have sex with men. Am J Public Health 2003, 93(6):939-942.

17. Relf MV, Huang B, Campbell J, Catania J: Gay identity, interpersonal violence, and HIV risk behaviors: an empirical test of theoretical relationships among a probability-based sample of urban men who have sex with men. J Assoc Nurses AIDS Care 2004, 15(2):14-26.

18. Nieves-Rosa LE, Carballo-Diéguez A, Dolezal C: Domestic abuse and HIVrisk behavior in Latin American men who have sex with men in New York city. J Gay Lesb Soc Serv 2000, 11(1):77-90.

19. Kalichman S, Benotsch E, Rompa D, Gore-Felton C, Austin J, Luke W, Simpson D: Unwanted sexual experiences and sexual risks in gay and bisexual men: Associations among revictimization, substance use, and psychiatric symptoms. J Sex Res 2001, 38(1):1-9.

20. Feldman MB, Ream GL, Diaz RM, El-Bassel N: Intimate partner violence and HIV sexual risk behavior among Latino gay and bisexual men: the role of situational factors. J LGBT Health Res 2007, 3(4):75-87.

21. Tanha M, Beck CJ, Figueredo AJ, Raghavan C: Sex differences in intimate partner violence and the use of coercive control as a motivational factor for intimate partner violence. J Interpers Violence 2010, 25(10):1836-1854.

22. Dutton MA, Goodman LA: Coercion in intimate partner violence: toward a new conceptualization. Sex Roles 2005, 52(11-12):743-756.

23. Stephenson R, de Voux A, Sullivan PS: Intimate partner violence and sexual risk-taking among men who have sex with men in South Africa. West J Emerg Med 2011, 12(3):343-347.

24. Finneran C, Chard A, Sineath C, Sullivan P, Stephenson R: Intimate partner violence and social pressure among gay men in six countries. West J Emerg Med 2012, 13(3):260-271.

25. Kashy DA, Kenny DA: The analysis of data fromdyads and groups. In Handbook of research methods in social psychology. Edited by Reis HT, Judd CM. New York: Cambridge University Press; 2000:451-477.

26. Kenny D, Kashy D, Cook W: Dyadic data analysis. New York: Guilford Press; 2006.

27. Mitchell JW, Champeau D, Harvey SM: Actor-partner effects of demographic and relationship factors associated with HIV risk within gay male couples. Arch Sex Behav 2012. Epub ahead of print.

28. Parsons JT, Starks TJ, Gamarel KE, Grov C: Non-monogamy and sexual relationship quality among same-sex male couples. J Fam Psychol 2012, 26(5):669-677.

29. Sullivan PS, White D, Rosenberg ES, Barnes J, Jones J, Dasgupta S, O'Hara B, Scales L, Salazar LF, Wingood G, Diclemente R, Wall KM, Hoff C, Gratzer B, Allen S, Stephenson R: Safety and acceptability of couples HIV testing and counseling for US men who have sex with men: a randomized prevention study. J Int Assoc Provid AIDS Care 2013 [Epub ahead of print].

30. Sullivan PS, Wall KM, O'Hara B, Jones J, Barnes J, DiClemente R, Hoff C, Scales L, Salazar LF, Sanchez T, White D, Wingood G, Allen S, Stephenson R: The prevalence of undiagnosed HIV serodiscordance among male couples presenting for HIV testing. Arch Sex Behav 2014, 43(1):173-180.

31. Straus MA: Measuring intrafamily conflict and violence: the conflict tactics (CT) scales. J Marriage Fam 1979, 41:75-88.

32. Cook W, Kenny D: The actor-partner interdependence model: a model of bidirectional effects in developmental studies. Int J Behav Dev 2005, 29(2):101-109.
33. McMahon JM, Pouget ER, Tortu S: A guide for multilevel modeling of dyadic data with binary outcomes using SAS PROC NLMIXED. Comput Stat Data Anal 2006, 50(12):3663-3680.

34. Flom PL, MCMahon JM, Pouget ER: Using PROC NLMIXED and PROC GLMMIX to analyze dyadic data with a dichotomous dependent variable. In SAS Global Forum, Paper 179-2007. Orlando, FL: SAS; 2007.

35. Bartholomew K, Regan KV, Oram D, White MA: Correlates of partner abuse in male same-sex relationships. Violence Vict 2008, 23(3):344-360.

36. World Health Organization: Preventing intimate partner and sexual violence against women: taking action and generating evidence. Geneva: World Health Organization; 2010

37. Rabin RF, Jennings JM, Campbell JC, B-M MH: Intimate partner violence screening tools. Am J Prev Med 2009, 36(5):439-445.

38. Aulivola M: Outing domestic violence: affording appropriate protections to gay and lesbian victims. Fam Court Rev 2004, 42:162-177.

39. Ard KL, Makadon HJ: Addressing intimate partner violence in lesbian, gay, bisexual, and transgender patients. J Gen Intern Med 2011, 26(8):930-933.

40. Peterman LM, Dixon CG: Domestic violence between same-sex partners: Implications for counseling. J Couns Dev 2003, 81(1):40-47.

41. Koblin BA, Torian L, Xu G, Guilin V, Makki H, Mackellar D, Valleroy L: Violence and HIV-related risk among young men who have sex with men. AIDS Care 2006, 18(8):961-967.

doi:10.1186/1471-2458-14-209

Cite this article as: Wall et al: Actor-partner effects associated with experiencing intimate partner violence or coercion among male couples enrolled in an HIV prevention trial. BMC Public Health 2014 14:209.

\section{Submit your next manuscript to BioMed Central and take full advantage of:}

- Convenient online submission

- Thorough peer review

- No space constraints or color figure charges

- Immediate publication on acceptance

- Inclusion in PubMed, CAS, Scopus and Google Scholar

- Research which is freely available for redistribution

Submit your manuscript at www.biomedcentral.com/submit
C Biomed Central 